\title{
Electron Transfer Dissociation of Doubly Sodiated Glycerophosphocholine Lipids
}

\author{
Xiaorong Liang, ${ }^{a}$ Jian Liu, ${ }^{a}$ Yves LeBlanc, ${ }^{\mathrm{b}}$ Tom Covey, ${ }^{\mathrm{b}}$ \\ A. Celeste Ptak, ${ }^{\mathrm{c}}$ J. Thomas Brenna, ${ }^{\mathrm{c}}$ and Scott A. McLuckey ${ }^{\mathrm{a}}$ \\ ${ }^{a}$ Department of Chemistry, Purdue University, West Lafayette, Indiana, USA \\ ${ }^{\mathrm{b}}$ MDS SCIEX, Concord, Ontario, Canada \\ ${ }^{c}$ Division of Nutritional Sciences, Cornell University, Ithaca, New York, USA
}

\begin{abstract}
The ability to generate gaseous doubly charged cations of glycerophosphocholine (GPC) lipids via electrospray ionization has made possible the evaluation of electron-transfer dissociation (ETD) for their structural characterization. Doubly sodiated GPC cations have been reacted with azobenzene radical anions in a linear ion trap mass spectrometer. The ion/ion reactions proceed through sodium transfer, electron-transfer, and complex formation. Electron-transfer reactions are shown to give rise to cleavage at each ester linkage with the subsequent loss of a neutral quaternary nitrogen moiety. Electron-transfer without dissociation produces $[\mathrm{M}+$ $2 \mathrm{Na}]^{+\cdot}$ radical cations, which undergo collision-induced dissociation (CID) to give products that arise from bond cleavage of each fatty acid chain. The CID of the complex ions yields products similar to those produced directly from the electron-transfer reactions of doubly sodiated GPC, although with different relative abundances. These findings indicate that the analysis of GPC lipids by ETD in conjunction with CID can provide some structural information, such as the number of carbons, degree of unsaturation for each fatty acid substituent, and the positions of the fatty acid substituents; some information about the location of the double bonds may be present in low intensity CID product ions. (J Am Soc Mass Spectrom 2007, 18, 1783-1788) (c) 2007 American Society for Mass Spectrometry
\end{abstract}

$\mathrm{W}$ ith the advent of electrospray ionization (ESI) $[1,2]$ and matrix-assisted laser desorption ionization (MALDI) [3, 4], the analysis of lipids using tandem mass spectrometry (MS) has been greatly facilitated since these techniques can generate the intact gaseous pseudo-molecular ions for most lipids ranging from simple fatty acids to complex lipids [5-10]. Among the various complex lipids, glycerophospholipids (GPLs) perform two important biological functions: one is making up most of the membranes of mammalian cells, and the other is acting as secondary messengers in metabolism [11, 12]. The structural determination (identities and positions of the fatty acid substituents) of GPLs for all five subclasses has been made via CID of negative ions formed by either ESI, fast atom bombardment $(\mathrm{FAB})$, or MALDI $[5,13,14]$. Among the five main subclasses of GPLs, which are differentiated by the head-group (e.g., ethanolamine, choline, serine, glycerol, or inositol), glycerophosphocholine (GPC) species generally give stronger signals in positive ion mode than in negative mode due to the fixed charge on the quaternary nitrogen. The structural information mentioned above can be obtained by CID

Address reprint requests to Dr. S. A. McLuckey, Department of Chemistry, Purdue University, 1393 Brown Laboratories, West Lafayette, IN 479072084, USA. E-mail: mcluckey@purdue.edu. of alkali adducts of GPC species generated in positive ion ESI-MS [15]. Little or no information regarding the location of the double bonds in GPCs has been reported by these methods.

Both electron capture dissociation (ECD) [16-19] and electron-transfer dissociation (ETD) [20-23] have been shown to be particularly useful in the structural determination of proteins and peptides [24-27]. This is mainly because more extensive sequence information can often be obtained via ECD or ETD than via CID and because, unlike CID, labile post-translational modifications are often retained, which is particularly valuable in establishing their location in the sequence [21, 28]. Thus, it is of interest to explore the ETD and ECD behavior of other ions derived from bio-molecules of interest.

In this communication, we report results from ion/ ion electron-transfer reactions of doubly sodiated GPC lipids. The major ETD channels show preferential cleavage at ester linkages. Thus, the carbon numbers and degrees of unsaturation for each chain can be readily determined. Electron-transfer without dissociation produces $[\mathrm{M}+2 \mathrm{Na}]^{+\cdot}$ ions that fragment to give products that arise from cleavage of the lipid backbone when subjected to collision-induced dissociation (CID). In addition, subsequent CID of the singly charged radical cations formed during the electron-transfer reaction 
appears to be capable of yielding a limited degree of information regarding the positions of the double bonds.

\section{Experimental}

\section{Materials}

Chloroform and methanol were purchased from Mallinckrodt (Phillipsburg, NJ). Sodium salts and azobenzene were obtained from Sigma-Aldrich (St. Louis, MO). The 1-stearoyl-2-arachidonyl-sn-glycerol3-phosphocholine [(18:0/20:4)-GPC] and 1-stearoyl-2docosahexaenoyl-sn-glycerol-3-phosphocholine [(18:0/ 22:6)-GPC] lipids were obtained from Avanti Polar Lipids (Birmingham, AL) and used without further purification. These GPC lipids were dissolved to 0.5 $\mathrm{mg} / \mathrm{mL}$ in a 50/50 (vol/vol) methanol/chloroform solution with $1 \mathrm{mM}$ (final concentration) $\mathrm{NaCl}$ added for generation of sodium adducts while $1 \%$ ( $\mathrm{vol} / \mathrm{vol}$ ) acetic acid was added for singly protonated GPC formation by positive nano-ESI. It was noted that relatively low interface voltage gradients tended to maximize observation of the doubly charged ions.

\section{Mass Spectrometry}

All experiments were performed using a prototype version of a Q TRAP mass spectrometer [29] (Applied Biosystems/MDS SCIEX, Concord, Ontario, Canada) equipped with a home-made dual nano-ESI/APCI source, which was described in detail elsewhere [30]. All the electronics were controlled by Daetalyst 3.14 software, a research version of software provided by MDS SCIEX.

A typical scan function for an ion/ion electrontransfer experiment consists of the following steps: positive ion injection into Q2 LIT (100 ms), anion injection into Q2 LIT (100 ms), mutual storage of cations and anions in Q2 LIT (400 ms), and transfer of ion/ion reaction product ions to mass analyzer Q3 (50 ms) for mass analysis. For an ion/ion electron-transfer reaction experiment, the positive high voltage power supply connected to the nano-ESI wire was pulsed on to generate analyte ions. Analyte ions were isolated by Q1 in rf/DC mode and injected axially into the Q2 LIT with nitrogen as the buffer gas at a pressure of $\sim 5$ mTorr. These ions were cooled in Q2 for $30 \mathrm{~ms}$, during which time the high voltage on this emitter was turned off. After the cooling step, the power supply connected to the APCI wire, which was operated in the negative polarity, was triggered on to generate the electrontransfer reagent anions. These reagent anions were isolated by Q1 in rf/DC mode before they entered Q2 LIT with relatively low kinetic energies $(\sim 5 \mathrm{eV})$. During this period, the DC potentials on the Q2 containment lenses, as well as on the Q2 rods themselves, were adjusted to a common value while an auxiliary rf voltage was applied to IQ3 lens. In the subsequent mutual ion polarity storage step, the potential applied to the APCI emitter was turned off and the auxiliary rf signals were applied to both containment lenses (i.e., IQ2 and IQ3) to store ions axially. After a defined period of mutual storage, the residual reagent ions were ejected from Q2 by applying attractive DC potentials to the Q2 containment lenses while the auxiliary rf signals were terminated. Then the positively charged product ions arising from ion/ion electron-transfer reactions, as well as the residual precursor ions, were transferred from Q2 to Q3, and cooled for $50 \mathrm{~ms}$ before they were subjected to mass selective axial ejection (MSAE) [31] using a supplementary rf signal at a frequency of 380 $\mathrm{kHz}$. When CID experiments on the product ions resulting from the ETD reactions were desired, the product ions were isolated in Q3 first in rf/DC mode and subsequently subjected to activation by applying an appropriate auxiliary AC on one pair of the Q3 rods.

\section{Results and Discussion}

The ability to generate multiply charged positive ions of GPCs is a necessary condition for employing ETD in the analysis of GPCs. Figure 1a shows the nano-ESI spectrum of sodiated adducts of (18:0/20:4)-GPC. The relative abundances of doubly sodiated and singly sodiated adducts are largely determined by the solution and atmosphere/vacuum interface conditions. The ion/ion reactions between isolated doubly sodiated adducts of (18:0/20:4)-GPC and singly charged azobenzene radical anions (shown in Figure $1 \mathrm{~b}$ ) give rise to the mass spectrum of Figure 1c. The main reaction products can be grouped into three classes: (1) sodium transfer from the doubly sodiated (18:0/20:4)-GPC to the azobenzene anion to form $[\mathrm{M}+\mathrm{Na}]^{+}$; (2) complex formation to give $[\mathrm{M}+2 \mathrm{Na}+\text { azobenzene }]^{+\cdot}$; and (3) electron-transfer from the azobenzene anion to $[\mathrm{M}+2 \mathrm{Na}]^{2+}$ to generate $[\mathrm{M}+$ $2 \mathrm{Na}]^{+\cdot}$ (i.e., electron-transfer without dissociation) and [M $+2 \mathrm{Na}-267]^{+},[\mathrm{M}+2 \mathrm{Na}-287]^{+},[\mathrm{M}+2 \mathrm{Na}-15]^{+}$, and $[\mathrm{M}+2 \mathrm{Na}-59]^{+}$ETD products. The losses of $15 \mathrm{Th}$ and 59 Th corresponds to loss of a methyl radical and trimethylamine, respectively, while the losses of 267 and 287 Th correspond to losses of each of the respective hydrocarbon chains in the form of a radical [ $\mathrm{RC}=\mathrm{O}]$. The former two products are reflective of the head group while the latter two products indicate that cleavage of the ester bonds is the dominant ETD process for doubly sodiated GPCs. From the masses of the latter two products, the carbon number and degree of unsaturation for each chain can be obtained.

Moreover, the relative abundances of ions reflecting the losses of the fatty acid substituents from ETD of doubly sodiated GPC species might indicate the positions of these substituents, although a much larger dataset is required to draw conclusions regarding this possibility. Comparison of the relative abundances of the ions at $m / z 568\left(\left[\mathrm{M}+2 \mathrm{Na}-\mathrm{R}_{2} \mathrm{C}=\mathrm{O}\right]^{+}\right)$and $m / z 588$ $\left(\left[\mathrm{M}+2 \mathrm{Na}-\mathrm{R}_{1} \mathrm{C}=\mathrm{O}^{+}\right)\right.$in Figure $1 \mathrm{c}$ indicates that the abundance of the ion resulting from the loss of the sn-2 


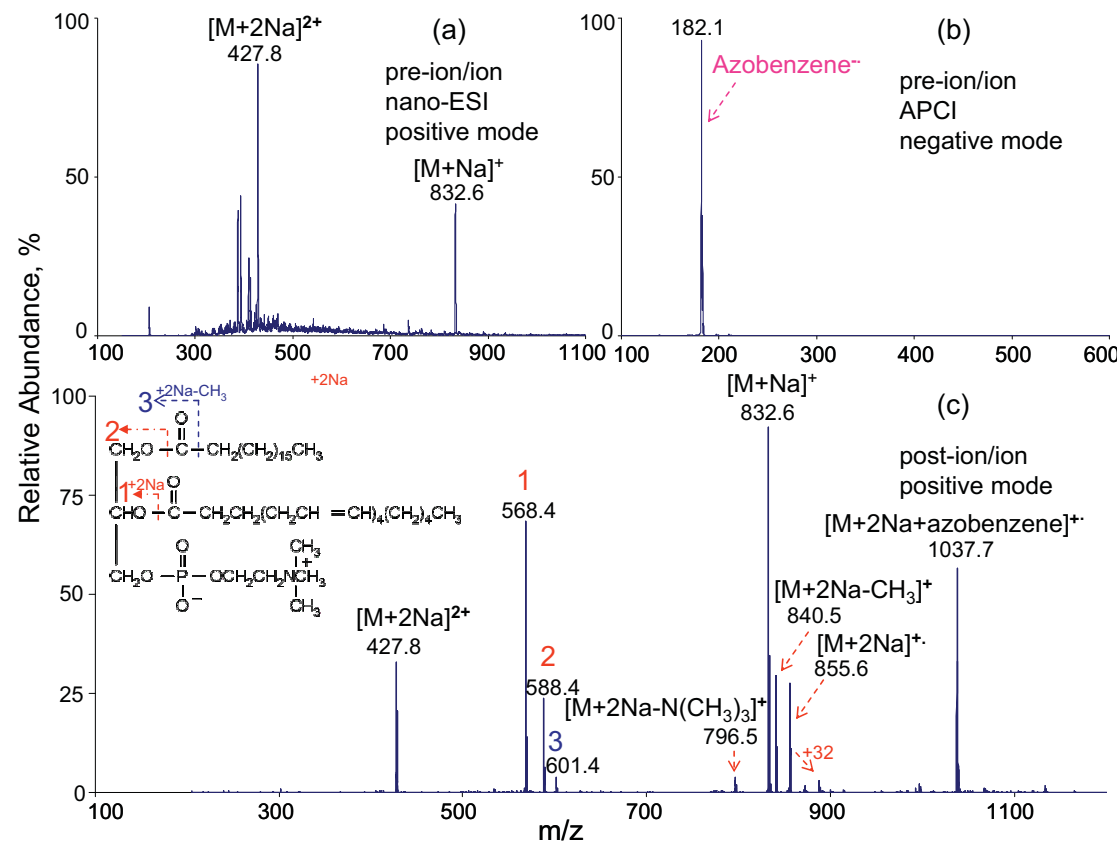

Figure 1. Mass spectra derived from (a) positive nano-ESI of (18:0/20:4)-GPC, (b) negative APCI of azobenzene, (c) ion/ion ETD reaction of isolated doubly sodiated (18:0/20:4)-GPC cations with singly charged azobenzene anions in Q2 LIT for $400 \mathrm{~ms}$.

substituent exceeds that of the ion resulting from the loss of the sn-1 substituent. The same observation has been made in the ETD results of doubly sodiated (18:0/22:6)-GPC lipids (data not shown), although with a difference in the relative abundances of the relevant product ions. This possible tendency stands in contrast to that from the CID of (18:0/20:4)-GPC lipids in the form of $[\mathrm{M}+\mathrm{Li}]^{+},[\mathrm{M}-15]^{-}$or $[\mathrm{M}+\text { acetate }]^{-}$, which generally show the preferential loss of the sn-1 acyl group [10, 15, 32].

The fragmentation behavior of these ETD product ions were further explored with $\mathrm{MS}^{3}$ experiments using CID. The results of $\mathrm{MS}^{3}$ experiments on the $\mathrm{m} / \mathrm{z} 568$ and 588 ions produced in the reaction discussed above are shown in Figure 2. Collisional activation in both cases leads exclusively to a loss of $103 \mathrm{Th}$, which corresponds to the neutral loss of $\left[\mathrm{O}\left(\mathrm{CH}_{2}\right)_{2} \mathrm{~N}\left(\mathrm{CH}_{3}\right)_{3}\right]$. While this loss provides information about the head group, no new information about the fatty acid substituents is forthcoming from this reaction. Although it would be desirable to perform $\mathrm{MS}^{4}$ to examine whether dissociation of the CID product can provide further structural information, the absolute signal of the ion in the $\mathrm{MS}^{3}$ spectrum is low, which compromises the practical utility of such an experiment.

Figure 3a shows the $\mathrm{MS}^{3}$ data resulting from the CID of the $[\mathrm{M}+\mathrm{Na}]^{+}$ions generated from ETD of the doubly sodiated (18:0/20:4)-GPC. The major dissociation channels are the losses of the trimethylamine head-group and the cholinephosphate group. Low abundance peaks at $\mathrm{m} / \mathrm{z} 489$ and 469 correspond to the loss of each fatty acid substituent in the form of [M $\mathrm{RCOOH}-59]^{+}$. Due to the LMCO of $\mathrm{m} / \mathrm{z} 200$ used for this in-trap ion activation, no ions below $\mathrm{m} / \mathrm{z} 200$ were recorded. For comparison, the CID spectrum of $[\mathrm{M}+$ $\mathrm{Na}]^{+}$generated directly from solution-phase via nanoESI is also included here. The results are shown in Figure $3 \mathrm{~b}$. The results are similar to the ions shown in Figure $3 \mathrm{a}$ in terms of ion identity and relative abundance. This result indicates that the singly sodiated (18:0/20:4)-GPC species formed via electron-transfer dissociation and directly via nano-ESI cannot be distinguished with ion-trap CID.

While CID of the major first generation ETD product ions does not provide additional information regarding the fatty acid chains, it is of interest to examine the ion/ion reaction products that do not lead to fragmentation. Figure 4a shows the CID product ion spectrum of the complex ions formed in the reaction of doubly sodiated (18:0/20:4)-GPC with the azobenzene anion. The product ion masses mirror those in the ETD spectrum of (18:0/20:4)-GPC and also include products ions at $m / z 465$ and 485 , which are the sequential fragmentation products of the ions at $m / z 568$ and 588, respectively (see the $\mathrm{MS}^{3}$ data of Figure 2). Figure $4 \mathrm{~b}$ shows the mass spectrum resulting from the collisional activation of the nondissociative electron-transfer product $[\mathrm{M}+2 \mathrm{Na}]^{+}$. The CID product ion at $\mathrm{m} / \mathrm{z} 549$ likely results from cleavage of the $\mathrm{C}-\mathrm{O}$ bond $\beta$ to the carbonyl carbon of the ester linkage (see Figure $4 \mathrm{~b}$ ) of 18:0 fatty acid chain. The CID product ion at $\mathrm{m} / \mathrm{z} 530$ probably results from cleavage of the $\mathrm{C}-\mathrm{O}$ bond $\beta$ to the carbonyl carbon of the ester linkage of 20:4 fatty acid chain with, perhaps, a hydrogen transfer to the ion, but the mass is observed at $1 \mathrm{Da}$ unit higher that expected. Along with the acyl chain losses, the concomitant losses of neutral trimeth- 


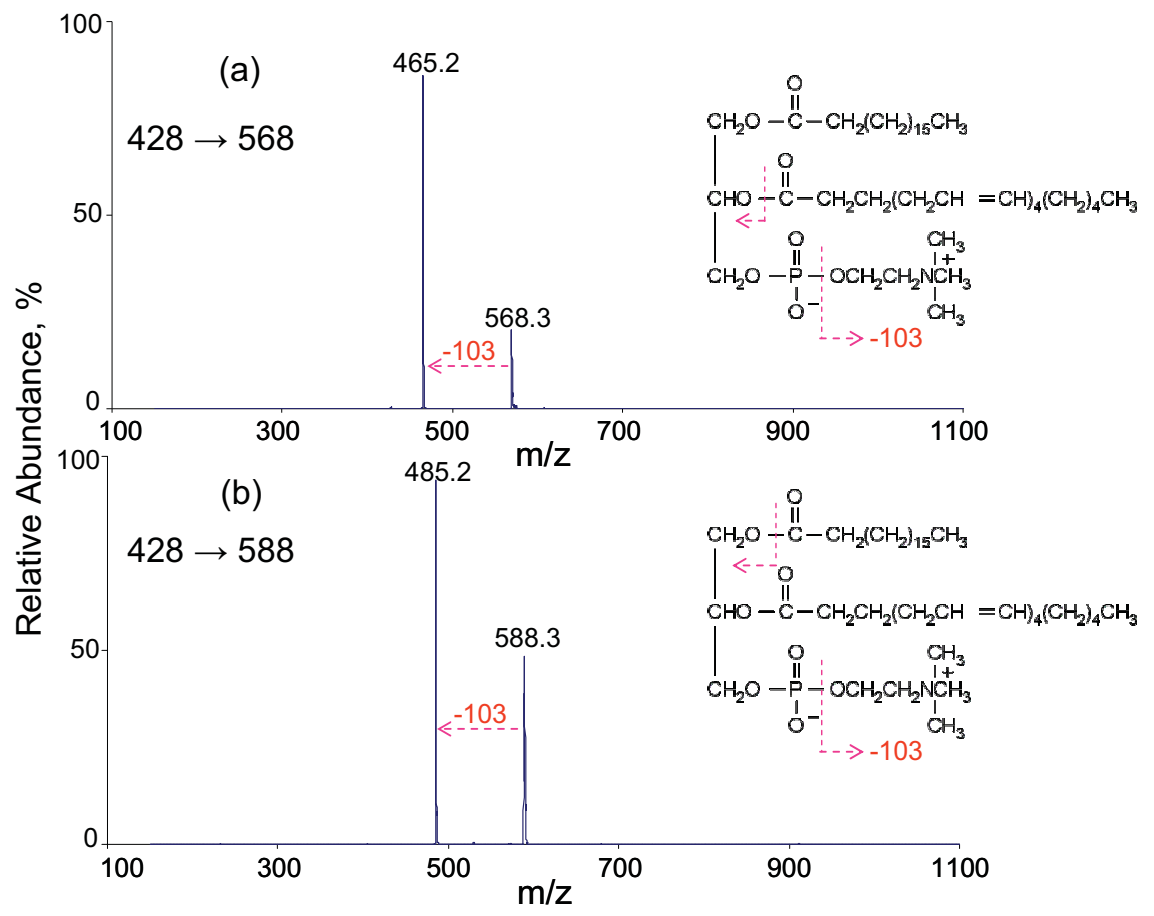

Figure 2. (a) $\mathrm{MS}^{3}$ of $m / z 568[\mathrm{M}+2 \mathrm{Na}-287]^{+}$. (b) $\mathrm{MS}^{3}$ of $m / z 588[\mathrm{M}+2 \mathrm{Na}-267]^{+}$.

ylamine head-group (59 Th) in both cases give rise to the ions of $m / z 490$ and 471, respectively. Product ion at $\mathrm{m} / \mathrm{z} 513$ is tentatively assigned to $\left[\mathrm{M}+2 \mathrm{Na}-\mathrm{R}_{1} \mathrm{COO}-\right.$ $\left.\mathrm{N}\left(\mathrm{CH}_{3}\right)_{3}\right]\left(\mathrm{R}_{1}=18: 0\right.$ fatty acid chain). The loss of $80 \mathrm{Th}$ from CID of $[\mathrm{M}+2 \mathrm{Na}]^{+\cdot}$ may arise from the loss of $\mathrm{HPO}_{3}$, although it requires a rearrangement mechanism during the CID process. The product ions shown in the $\mathrm{m} / \mathrm{z}$ range 200 to 470 include some consecutive mass

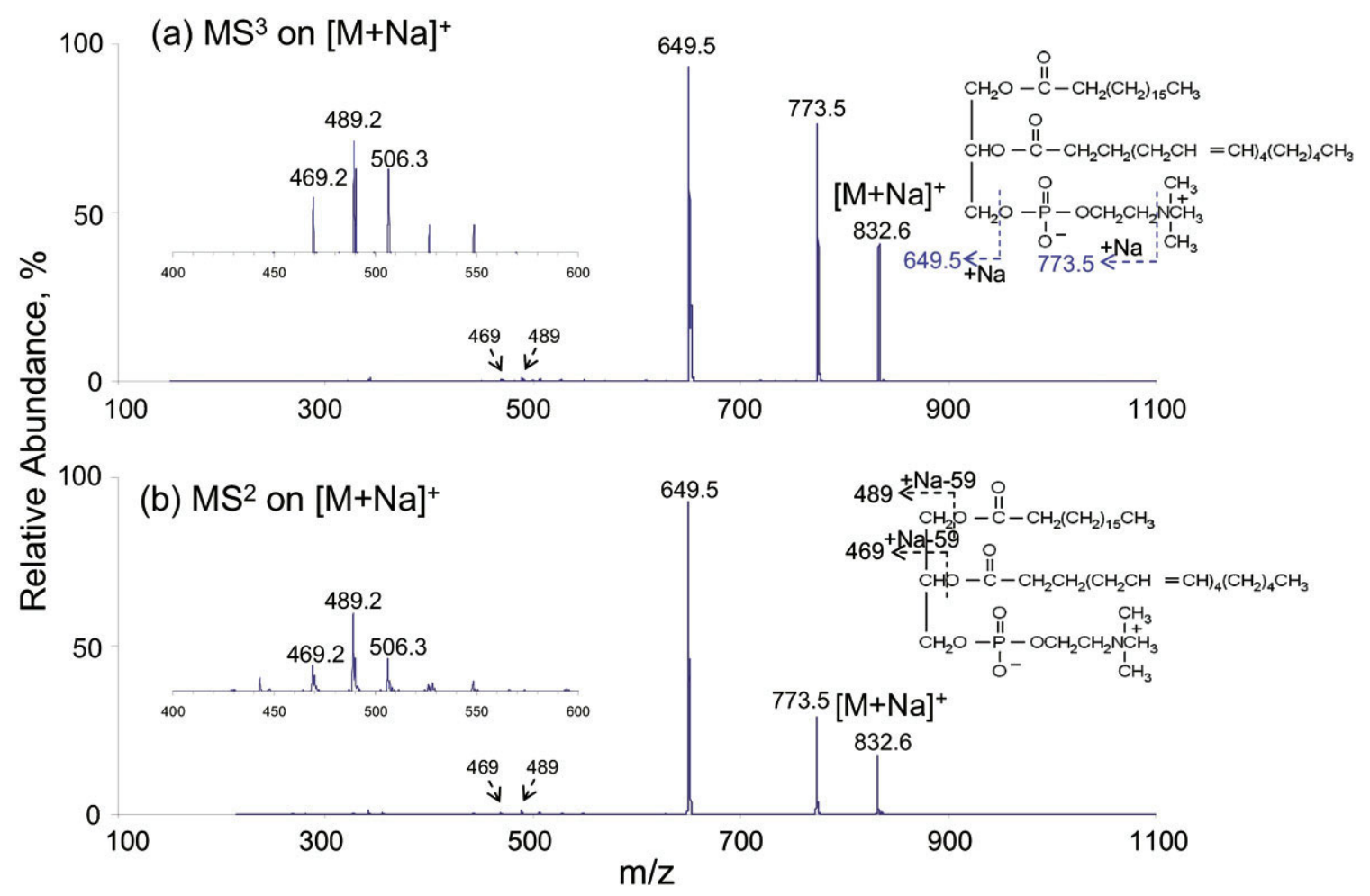

Figure 3. (a) $\mathrm{CID} \mathrm{MS}^{3}$ of $\mathrm{m} / \mathrm{z} 833$ generated from ETD of doubly sodiated (18:0/20:4)-GPCs. (b) CID MS $^{2}$ of $m / z 833$ generated from nano-ESI of (18:0/20:4)-GPCs solution. 


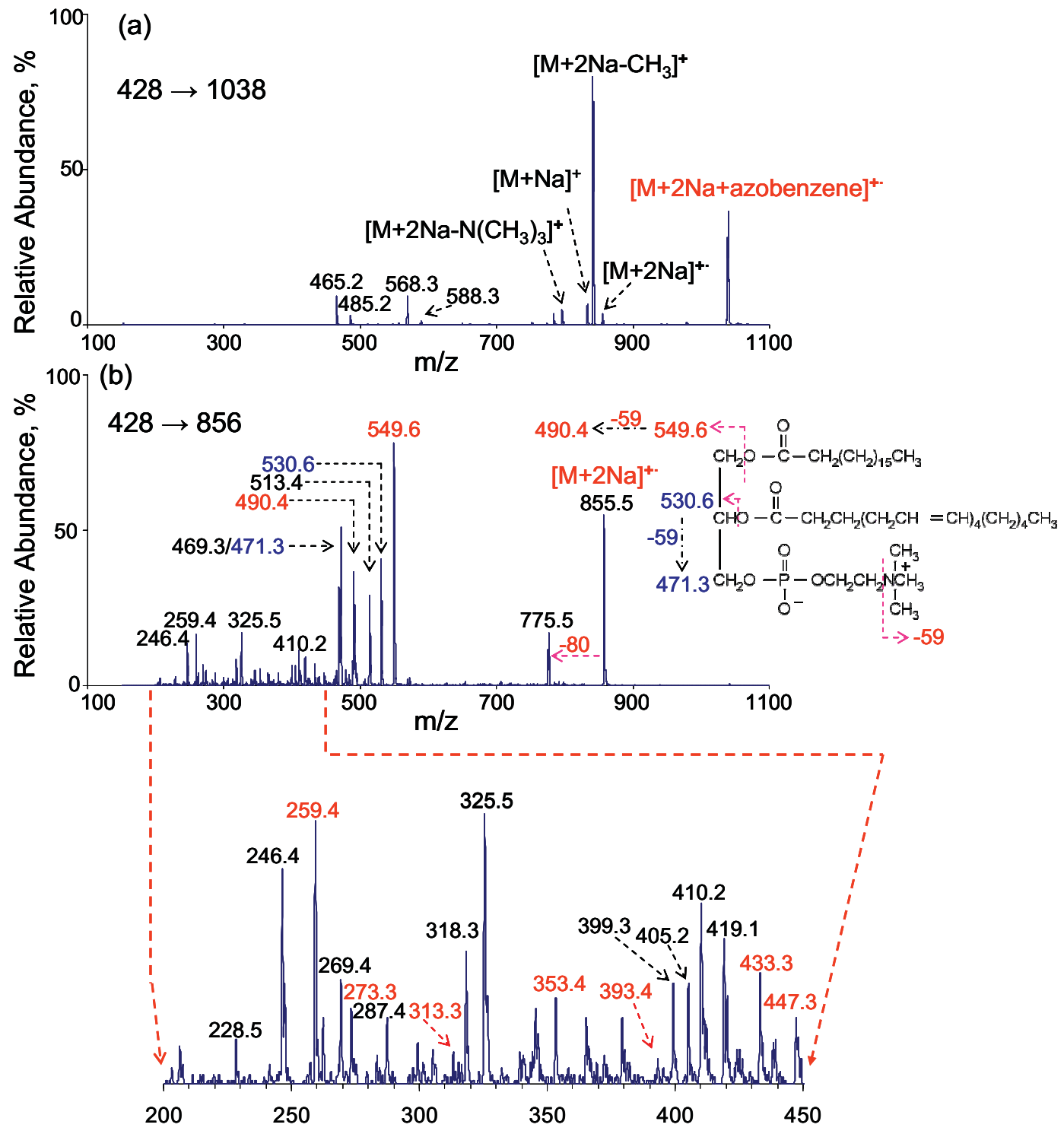

Figure 4. (a) $\mathrm{MS}^{3}$ of $m / z 1038[\mathrm{M}+2 \mathrm{Na}+\text { azobenzene }]^{+}$. (b) $\mathrm{MS}^{3}$ of $m / z 856[\mathrm{M}+2 \mathrm{Na}]^{+*}$.

differences of 14 Th and $40 \mathrm{Th}$. This leads to some information about cleavage along the sn-2 fatty acid chain (20:4). For example, Scheme 1 shows plausible cleavages that give rise to product ions of the indicate mass-to-charge ratios.

\section{Conclusions}

Ion/ion reactions between doubly sodiated GPC species result in sodium transfer to the anion, adduct formation, electron-transfer without dissociation, and

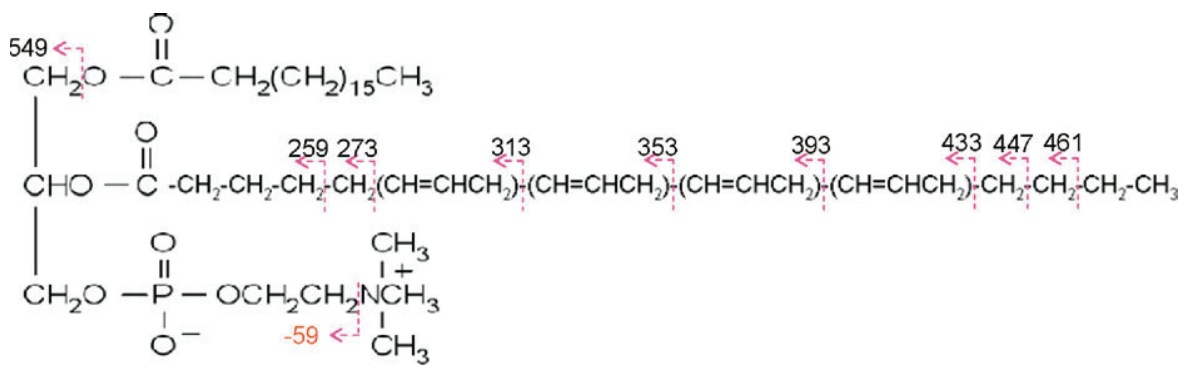

Scheme 1. Proposed fragmentation pathway for the location of the double-bond in (18:0/20:4)-GPC species. 
ETD of the cation. ETD products directly provide carbon number and degree of unsaturation. The relative abundances of the ions may also yield fatty acid position but too little data are in hand to draw a firm conclusion on this point. Electron-transfer without dissociation produces $[\mathrm{M}+2 \mathrm{Na}]^{+\cdot}$ ions, which fragment upon collisional activation to give products that correspond to bond cleavage of each fatty acid chain. The CID of complex ions generates products that are similar to those produced directly from the electron-transfer reactions of doubly sodiated GPC cations, in terms of ion identities, although with different relative abundances. These findings indicate that the ETD of doubly sodiated GPC lipids gives information similar to that derived from CID of alkali adducts. CID of the singly charged radical cations formed via electron-transfer may be able to yield some degree of information about double-bond positions but further work is warranted to assess this potential. In any case, the signal levels associated with the potentially informative ions are relatively low, which affects the overall sensitivity of the approach.

\section{Acknowledgments}

This work was sponsored by MDS SCIEX, an Industrial Associate of the Department of Chemistry and the National Institutes of Health, National Institute of General Medical Sciences under grants GM 45,372 and GM 071534.

\section{References}

1. Fenn, J. B.; Mann, M.; Meng, C. K.; Wong, S. F.; Whitehouse, C. M. Electrospray Ionization for Mass Spectrometry of Large Biomolecules. Science 1989, 246, 64-71.

2. Fenn, J. B.; Mann, M.; Meng, C. K.; Wong, S. F.; Whitehouse, C. M. Electrospray Ionization Principles and Practice. Mass Spectrom. Rev. 1990, 9, 37-70

3. Karas, M.; Bachman, D.; Bahr, U.; Hillenkamp, F. Matrix-Assisted Ultraviolet Laser Desorption of Nonvolatile Compounds. Int. J. Mass Spectrom. Ion Processes 1987, 78, 53-68.

4. Tanaka, K.; Waki, H.; Ido, Y.; Akita, S.; Yoshida, Y.; Yoshida, T. Protein and Polymer Analyses up to $m / z$ 100,000 by Laser Ionization Time-ofFlight Mass Spectrometry. Rapid Commun. Mass Spectrom. 1988, 2, 151-153.

5. Murphy, R. C.; Fiedler, J.; Hevko, J. Analysis of Nonvolatile Lipids by Mass Spectrometry. Chem. Rev. 2001, 101, 479-526.

6. Murphy, R. C.; Raetz, C. R.; Reynolds, C. M.; Barkley, R. M. Mass Spectrometry Advances in Lipidomica: Collision-Induced Decomposition of Kdo2-Lipid A. Prostaglandins Other Lipid Mediat. 2005, 77, 131-140.

7. Harvey, D. J. Matrix-Assisted Laser Desorption/Ionization Mass Spectrometry of Phospholipids. J. Mass Spectrom. 1995, 30, 1333-1346.

8. Kaufmann, R.; Wingerath, T.; Kirsch, D.; Stahl, W.; Sies, H. Analysis of Carotenoids and Carotenol Fatty Acid Esters by Matrix-Assisted Laser Desorption Ionization (MALDI) and MALDI Postsource-Decay Mass Spectrometry. Anal. Biochem. 1996, 238, 117-128.

9. Asbury, G. R.; Al-Saad, K.; Siems, W. F.; Hannan, R. M.; Hill, H. H., Jr. Analysis of Triacylglycerols and Whole Oils by Matrix-Assisted Laser Desorption/Ionization Time of Flight Mass Spectrometry. J. Am. Soc. Mass Spectrom. 1999, 10, 983-991.

10. Stubiger, G.; Belgacem, O. Analysis of Lipids Using 2,4,6Trihydroxyacetophenone as a Matrix for MALDI Mass Spectrometry. Anal. Chem. 2007, 79, 3206-3213.
11. Maxfield, F. R.; Tabas, I. Role of Cholesterol and Lipid Organization in Disease. Nature 2005, 438, 612-621.

12. Zeisel, S. H.; Blusztajn, J. K. Choline and Human Nutrition. Annu. Rev. Nutr. 1994, 14, 269-296.

13. Hsu, F. F.; Turk, J.; Owens, R. M.; Rhoades, E. R.; Russell, D. G. Structural Characterization of Phosphatidyl-Myo-Inositol Mannosides from Mycobacterium bovis Bacillus Calmette-Guérin by Multiple-Stage Quadrupole Ion-Trap Mass Spectrometry with Electrospray Ionization, I. PIMS and Lyso-PIMS. J. Am. Soc. Mass Spectrom. 2007, 18, 466-478.

14. Hsu, F. F.; Turk, J.; Owens, R. M.; Rhoades, E. R.; Russell, D. G. Structural Characterization of Phosphatidyl-Myo-Inositol Mannosides from Mycobacterium bovis Bacillus Calmette-Guérin by Multiple-Stage Quadrupole Ion-Trap Mass Spectrometry with Electrospray Ionization, II. Monoacyl- and Diacyl-PIMS. J. Am. Soc. Mass Spectrom. 2007, 18, 479-492.

15. Hsu, F. F.; Bohrer, A.; Turk, J. Formation of Lithiated Adducts of Glycerophosphocholine Lipids Facilitates Their Identification by Electrospray Ionization Tandem Mass Spectrometry. J. Am. Soc. Mass Spectrom. 1998, 9, 516-526.

16. Zubarev, R. A.; Kelleher, N. L.; McLafferty, F. W. Electron Capture Dissociation of Multiply Charged Protein Cations. A Nonergodic Process. J. Am. Chem. Soc. 1998, 120, 3265-3266.

17. Zubarev, R. A.; Kruger, N. A.; Fridricksson, E. K.; Lewis, M. A.; Horn, D. M.; Carpenter, B. K.; McLafferty, F. W. Electron Capture Dissociation of Gaseous Multiply-Charged Proteins is Favored at Disulfide Bonds and Other Sites of High Hydrogen Atom Affinity. J. Am. Chem. Soc. 1999, 121, 2857-2862.

18. Zubarev, R. A.; Horn, D. M.; Fridriksson, E. K.; Kelleher, N. L.; Kruger, N. A.; Lewis, M. A.; Carpenter, B. K.; McLafferty, F. W. Electron Capture Dissociation for Structural Characterization of Multiply Charged Protein Cations. Anal. Chem. 2000, 72, 563-573.

19. Zubarev, R. A. Reactions of Polypeptide Ions with Electrons in the Gas Phase. Mass Spectrom. Rev. 2003, 22, 57-77.

20. Syka, J. E.; Coon, J. J.; Schroeder, M. J.; Shabanowitz, J.; Hunt, D. F. Peptide and Protein Sequence Analysis by Electron Transfer Dissociation Mass Spectrometry. Proc. Natl. Acad. Sci. U.S.A. 2004, 101, $9528-$ 9533.

21. Coon, J. J.; Syka, J. E. P.; Schwartz, J. C.; Shabanowitz, J.; Hunt, D. F. Anion Dependence in the Partitioning between Proton and Electron Transfer in Ion/Ion Reactions. Int. J. Mass Spectrom. 2004, 236, 33-42.

22. Pitteri, S. J.; Chrisman, P. A.; Hogan, J. M.; McLuckey, S. A. Electron Transfer Ion/Ion Reactions in a Three-Dimensional Quadrupole Ion Trap: Reactions of Doubly and Triply Protonated Peptides with $\mathrm{SO}_{2}{ }^{-}$. Anal. Chem. 2005, 77, 1831-1839.

23. Gunawardena, H. P.; He, M.; Chrisman, P. A.; Pitteri, S. J.; Hogan, J. M. Hodges, B. D.; McLuckey, S. A. Electron Transfer Versus Proton Transfer in Gas-Phase Ion/Ion Reactions of Polyprotonated Peptides. J. Am. Chem. Soc. 2005, 127, 12627-12639.

24. Ge, Y.; Lawhorn, B. G.; El-Naggar, M.; Strauss, E.; Park, J. H.; Begley, T. P.; McLafferty, F. W. Top Down Characterization of Larger Proteins (45 kDa) by Electron Capture Dissociation Mass Spectrometry. J. Am. Chem. Soc. 2002, 124, 672-678.

25. Ge, Y.; El-Naggar, M.; Sze, S. K.; Oh, H. B.; Begley, T. P.; McLafferty, F. W.; Boshoff, H.; Barry, C. E. III. Top Down Characterization of Secreted Proteins from Mycobacterium Tuberculosis by Electron Capture Dissociation Mass Spectrometry. J. Am. Soc. Mass Spectrom. 2003, 14, 253-261.

26. Sze, S. K.; Ge, Y.; Oh, H.; McLafferty, F. W. Top-Down Mass Spectrometry of a $29 \mathrm{kDa}$ Protein for Characterization of Any Posttranslational Modification to Within One Residue. Proc. Natl. Acad. Sci. U.S.A. 2002, 99, 1774-1779.

27. Coon, J. J. Ueberheide, B. Syka, J. E. Dryhurst, D. D.; Ausio, J. Shabanowitz, J.; Hunt, D. F. Protein Identification Using Sequential Ion/Ion Reactions and Tandem Mass Spectrometry. Proc. Natl. Acad. Sci. U.S.A. 2005, 102, 9463-9468.

28. Stone, D. H.; Hemling, M. E.; Carr, S. A.; Horn, D. M.; Lindh, I.; McLafferty, F. W. Anal. Chem. 2001, 73, 19-22.

29. Hager, J. W. A New Linear Ion Trap Mass Spectrometer. Rapid Commun. Mass Spectrom. 2002, 16, 512-526.

30. Liang, X.; Xia, Y.; McLuckey, S. A. Alternately Pulsed Nanoelectrospray Ionization/Atmospheric Pressure Chemical Ionization for Ion/Ion Reactions in an Electrodynamic Ion Trap. Anal. Chem. 2006, 78, 3208-3212.

31. Londry, F. A.; Hager, J. W. Mass Selective Axial Ion Ejection from a Linear Quadrupole Ion Trap. J. Am. Soc. Mass. Spectrom. 2003, 14, 1130-1147.

32. Jackson, S. N.; Wang, H. Y.; Woods, A. S. In Situ Structural Characterization of Phosphatidylcholines in Brain Tissue Using MALDI-MS/MS. J Am. Soc. Mass Spectrom. 2005, 16, 2052-2056. 